ISSN 1518-3483

Licenciado sob uma Licença Creative Commons

\title{
O currículo escolar e o fim das utopias pedagógicas: distopia ou reposicionamento de apostas?
}

\section{School curriculum and the end of pedagogic utopias: dystopia or a repositioning of investments?}

\author{
Juares da Silva Thiesen*
}

Universidade Federal de Santa Catarina (UFSC), Florianópolis, SC, Brasil

\section{Resumo}

No artigo, organizado no âmbito do grupo de pesquisa em currículo, analisa-se a relação entre currículo, utopia e futuro a partir de referenciais presentes em abordagens do pensamento fundacional e pós-fundacional - duas matrizes teóricas a partir das quais se travam significativos embates nas ciências humanas em geral e na educação em particular. O problema que se coloca é se vivemos um tempo de distopia pedagógica e curricular em razão da emergência de abordagens que defendem o fim das metanarrativas e dos projetos de futuro na educação ou trata-se de um reposicionamento de apostas com vistas a manutenção do modelo educacional vigente. Inicialmente apresentam-se elementos das utopias pedagógicas que tão bem marcaram a modernidade pela hegemonia do

* JST: Doutor em Educação, e-mail: juares.thiesen@ufsc.br 
pensamento fundacional e o lugar do currículo nesse cenário. Em seguida discutem-se aspectos da dimensão pós-fundacional na educação e suas influências no campo do currículo, especialmente os elementos trazidos pelas teorias pós-estruturalistas, para finalmente defender-se que a atual sociedade burguesa vive tempos de acentuado fundacionismo tanto no âmbito das políticas educacionais e curriculares quanto nas formas de avaliação dos resultados da aprendizagem escolar e que não há, portanto, evidências de distopia pedagógica.

Palavras-chave: Currículo. Utopia. Futuro. Distopia.

\section{Abstract}

This article is organized in the realm of the research group in curriculum and analyzes the relationship between curriculum, utopia and future. It is based on references from the foundational and post-foundational thinking approaches - two theoretical matrixes based on which significant conflicts have been waged in the human sciences in general and in education in particular. The problem that is raised is if we are living in a time of pedagogical and curricular dystopia due to the emergence of approaches that defend the end of metanarratives and of projects for the future in education, or if there is a repositioning of investments to maintain the current educational model. Initially, elements of the pedagogical utopias are presented that strongly mark modernity by the hegemony of foundational thinking and the place of the curriculum in this scenario. The paper then discusses aspects of the post-functional dimension in education and its influences on the field of curriculum, especially the elements raised by post-structuralist theories. Finally, it affirms that current bourgeois society is experiencing an accentuated foundationalism in the realms of educational and curricular policies and in the forms of evaluation of the results of school learning. Therefore, there is no evidence of a pedagogical dystopia.

Keywords: Curriculum. Utopia. Future. Dystopia. 


\section{Introdução}

Dentre os tantos "fins" que se anunciam nesse tempo da história estaríamos no fim da pansofia educacional e curricular moderna? O propalado esgotamento da escola de conhecimento universal e homogêneo como o caminho para a educação do homem culto e emancipado estaria com seus dias contados pelo simples fim do argumento que a criou ou são as condições objetivas do mundo que sinalizam seu esfacelamento?

A crise instalada na educação escolar formal e particularmente nas prescrições curriculares que engendram seu movimento revela que estamos sem alternativas para esta secular instituição ou estamos atravessando uma tempestade que exige que mudemos nossas apostas e estratégias? Nunca tivemos tantas alternativas teóricas e opções metodológicas, mas contraditoriamente nunca tivemos tantas dúvidas e frustrações.

Afinal de contas, será mesmo o fim da grande utopia pedagógica moderna iniciada por Comenius, assumida depois como ideal pelo estado capitalista e mais recentemente incluída nos discursos do mercado ou estamos em meio a uma tormenta com ventos e trovões de procedência unicamente discursiva? Enfim, ainda há apostas a fazer para a escola e para o currículo do futuro?

É, pois, sobre essa problemática de que trata o presente artigo. Inscrito no conjunto das investigações que vimos desenvolvendo no grupo de pesquisa em currículo na Universidade, o trabalho objetiva discutir os atuais cenários do campo curricular, em particular, a relação entre currículo, utopia e futuro - temática que vem ganhando espaço em trabalhos como o de Michael Young (2002), Mariano Narodoswski (2006), Antônio Flávio Barbosa Moreira (1997), Cristián Cox (2001), Peter McLaren (2001) e outros.

$\mathrm{Na}$ análise dessa relação leva-se em conta aspectos sobre o atual debate em torno do que pressupõem as duas grandes matrizes teóricas a partir das quais se dá o embate nas ciências humanas em geral e da educação em particular. $\mathrm{Na}$ matriz mais estabelecida historicamente está o pensamento fundacional, nela incluídas as perspectivas epistemológicas 
da ciência moderna, particularmente a sociologia positivista e o marxismo tradicional além de suas derivações; todas sustentadas na ideia "da possibilidade universal" seja do alcance do conhecimento verdadeiro e/ou de uma "outra sociedade" - melhor, obviamente. Na outra matriz está o pensamento pós-fundacional genericamente representado pelas perspectivas relativistas, pós-modernas ou pós-estruturalistas, todas assentadas na negação da possibilidade de qualquer "fundamento último", portanto na rejeição a qualquer ideia de conhecimento universal, invariante, absoluto (MARCHART, 2009).

Sem a pretensão de aprofundar qualquer das perspectivas acima identificadas, busca-se nesse texto, como recorte, analisar implicações dessas matrizes de pensamento sobre o campo do currículo escolar, seja nos termos do debate teórico ou mesmo da política curricular. Em sentido stricto, pretende-se discutir se a emergência de perspectivas pós-fundacionais no campo do currículo escolar pode ser entendida como a primeira experiência histórica de uma distopia no campo da educação escolar.

Metodologicamente, organiza-se o artigo em três tópicos: no primeiro apresentam-se alguns elementos do pensamento fundacional que sustentam o campo curricular, com destaque para as abordagens que afirmam, por um lado, a possibilidade de um currículo escolar científico, eficiente e performativo e, por outro, a possibilidade de um currículo socialmente emancipador e transformador. No segundo tópico apresentam-se elementos da dimensão pós-fundacional, em especial as formulações das chamadas teorias pós-estruturalistas e pós-críticas do campo do currículo - perspectivas que rejeitam a ideia de conhecimento curricular relevante, verdadeiro e universal. Na última sessão argumenta-se que a sociedade burguesa vive tempos de reposicionamento de estratégias educacionais e curriculares sem que esse movimento signifique o fim das grandes utopias pedagógicas. 


\section{O currículo da escola burguesa - elementos de uma utopia pedagógica pela hegemonia do pensamento fundacional}

Se possível que demarquemos o surgimento de uma pedagogia utópica para o mundo ocidental moderno, sem dúvida, a pansofia (Panorthosia) de John Amos Comenius (1592-1670) revela-se emblemática. Seu projeto enciclopédico e universalista era, resumidamente, compilar todo o conhecimento humano dispondo-o de maneira que todas as pessoas tivessem acesso, quaisquer que fossem as informações desejadas. E, para tanto, se empenhara na unificação da linguagem e do método de estudo. Sua panorthosia é a descrição de uma república ideal, pela qual tomamos conhecimento de suas leis, instituições e costumes. Ainda que tenha buscado inspiração maior nas ideias de Francis Bacon (1561-1626), a utopia de Comenius foi mais colada ao seu tempo, foi a proposta objetiva para outra sociedade com apelo à sua realização.

A pedagogia comeniana assenta-se, portanto, como uma filosofia universal pelo encontro finalístico entre conhecimento, arte, religião, natureza e estado. Sua atenção especial à construção de um método de transmissão do conhecimento revela a convicção na possibilidade de uma ampla reforma social. Nesse sentido, pedagogia e currículo ocupam lugar fundamental, na medida em que são estes os instrumentos que permitem que "todos aprendam totalmente tudo" (COMENIUS, 1997, p. 103).

A escola burguesa, nutrindo-se do espírito da pedagogia pansófica de Comenius, segue seu percurso buscando na razão humana e na força da ciência empírica as respostas universais para as questões sociais. O conhecimento, marca da grande reforma que se operava no mundo ocidental, estaria contemplado seja pelas luzes do esclarecimento, seja pela mecânica da experiência objetiva ou ainda pelas utopias revolucionárias de matriz marxista.

Como analisa Narodowiski (2006), ao longo dos últimos séculos variaram os conteúdos da formulação utópica e também a compreensão sobre o caráter genérico do ser que é o homem, entretanto, todas as pedagogias continuaram coincidindo em que educar é educar um homem para 
uma finalidade totalizadora, que educar é formar um homem para uma determinada sociedade. Poderão os pedagogos discutir initerruptamente acerca de qual homem para qual sociedade, porém concordarão, desde John Loche (1632-1704) a Paulo Freire (1921-1997) ou de João Baptista de La Salle (1651-1719) à John Dewey (1859-1952) que é preciso educar o homem se há este que ser tal ou qual.

É preciso deixar claro, todavia, que as utopias pedagógicas da modernidade diferem de utopias clássicas como a de Thomas Morus (1478 - 1535), Tommaso Campanella (1568-1639), Francis Bacon (1561-1626), Saint Simon (1760-1825), Fourier (1772-1837), Robert Owen (17711858), Pierre Joseph Proudhon (1809-1865), Aldous Huxley (1894-1963) e George Orwell (1903-1950), por exemplo. Enquanto as utopias clássicas constituíram formulações românticas ou formas criativas de protesto expressadas na conformação de outros mundos, as utopias pedagógicas orientam-se pela eterna busca de mundos possíveis, seja pela luta sociopolítica de rejeição aos modelos estabelecidos ou pela superação de modelos que se esgotam no descompasso das demandas sociais mais amplas.

Para todas as utopias pedagógicas há um fundamento último, há um ou mais princípios de universalidade, há um ideal como ponto de chegada. Em todas há também um currículo que orienta seu movimento interno, que dá consistência ao seu propósito, que define qual conhecimento para qual formação e qual perfil de sujeito para qual sociedade. $\mathrm{O}$ currículo é o território (ARROYO, 2011) onde se travam as tensões em torno dos significados políticos da formação com vistas a fins específicos (APPLE, 2002). Assim, historicamente constrói-se, por exemplo, um currículo para a pedagogia burguesa, um currículo para a pedagogia socialista, um currículo para a pedagogia da liberdade, um currículo para a pedagogia dos grupos sociais excluídos, um currículo para a pedagogia das competências produtivas.

O que designa o caráter fundacional das pedagogias modernas é o fato de elas sustentarem-se por uma ideia 'construída' de formação humana e, a partir desse pressuposto, organizarem currículos que respondam a 'uma' função social para a escola. Como aponta Fullat (1995), 
a escola, por meio de sua organização interna [e de seu currículo], procurou responder às expectativas universais da sociedade ancorando-se em filosofias também fundacionais, assim caminhou no sentido de formar o homem positivo da ciência, o homem anarquista, o homem atemporal do idealismo cristão, o homem comunista, o homem liberdade, o homem tecnológico etc.

A utopia dessas pedagogias, entendemos, está na fixação de um "propósito ultimo" na convicção sobre a possibilidade de um lugar de chegada ou de um "estado ideal". Como chegar ao homem livre, ao homem conhecimento, ao homem emancipado, à sociedade equânime? Qual prescrição curricular pode garantir uma formação individual e coletiva que, como ponto de partida, considere os princípios e os fundamentos a priori estabelecidos e como ponto de chegada expresse estes mesmos princípios e fundamentos convertidos na forma do comportamento humano esperado? Somente no nível da utopia essa totalidade se explicaria?

Se tomamos o currículo enciclopédico e o científico como os dois grandes modelos curriculares que fabricaram a escola moderna [ou que foram por ela fabricados], veremos que ambos trazem consigo a expressão da utopia pedagógica. Tanto para os adeptos do liberalismo quanto para os filiados na tradição socialista, a escola deve assumir uma função social determinada. Para os iluministas a escola deve cumprir o papel de "civilizadora dos homens" como sonharam, por exemplo, François Rabelais (1483-1553), Marquis de Condorcet (1743-1794) e Jean-Jaques Rosseau (1712-1778). Desse modo seu currículo deve contemplar as artes, a ciência, a poesia e a filosofia. Para Antônio Gramsci (1891-1937) a escola deveria ser o lugar da emancipação das massas, portanto seu currículo incluiria os mesmos saberes e conhecimentos oportunizados à elite. $\mathrm{Na}$ politécnica de Karl Marx (1818-1883) a escola humanizadora e emancipatória do proletariado deveria associar o conhecimento enciclopédico com o do trabalho fabril. Para os eficientistas norte-americanos John Franklin Bobbit (1876-1956) e Ralph W. Tyler (1902-1994), a escola deveria responder às expectativas do crescimento econômico da sociedade, portanto, seu currículo responderia objetivamente à formação humana para essa 
demanda. Para Paulo Freire o currículo deveria ser o da autonomia, o da libertação do oprimido e o da esperança.

Patrícia Piozzi (2007), ao apresentar e discutir as utopias revolucionárias e a educação pública moderna, ilustra bem o fundacionismo presente nas diferentes filosofias e abordagens pedagógicas apontando o caráter finalístico, portanto teleológico, de cada uma. Notadamente essas pedagogias projetam na educação um ideal de mundo e de sociedade inalcançáveis em sua totalidade. Assumindo a expressão de Condorcet a autora mostra-nos um bom exemplo de utopia na educação revelando a força do currículo na fabricação da escola:

O franqueamento do acesso a todos e os "currícula" voltados a expandir as faculdades intelectuais e inventivas, unidos a políticas de ampliação dos direitos sociais, iriam paulatinamente reduzir e, enfim, extinguir a desigualdade, transformando a divisão do trabalho em uma cooperação voluntária e complementar entre os talentos, isenta dos conflitos inerentes à estratificação das oportunidades entre as nações e classes ricas e pobres, entre os detentores do conhecimento e aqueles que dele são privados (p. 721).

A classificação que faz Suchodolski (1907-1992) é igualmente ilustrativa para a análise que estamos fazendo. $\mathrm{Na}$ obra $A$ pedagogia e as grandes correntes pedagógicas, o autor sintetiza as correntes pedagógicas em duas matrizes: a pedagogia da essência e a da existência. A primeira sustenta-se por um evidente fundacionismo idealista na medida em que projeta buscar na formação humana "a educação nos princípios imutáveis que determinam a vocação eterna e universal do homem" (SUCHODOLSKI, 1978, p. 109). Não resta dúvida de que o currículo da escola burguesa contemporânea carrega forte carga desse ideário utópico, sobretudo pelos vínculos históricos constituídos entre igreja e escola. Até mesmo as atuais abordagens neoconservadoras mantêm elementos dessa tradição em seus propósitos curriculares.

$\mathrm{Na}$ análise que faz o filósofo é possível perceber que, embora a pedagogia da existência esteja assentada em uma matriz com menor 
evidência finalística, sua perspectiva sociopolítica não elimina o sentido teleológico de vez que reposiciona o futuro na ação do presente como pedagogia que promova o sentido da vida dos sujeitos em sociedade e nela a perspectiva de evolução social está preservada, já que busca-se a "realização do sujeito como progresso humano" (LIMA, 2009). Obviamente, é no âmbito dessa abarcadora perspectiva filosófica que se encontram as formulações do pensamento pós-fundacional com suas derivações para as chamadas pedagogias pós-modernas ou pós-estruturalistas, espaços teóricos onde as concepções de currículo passam a ser visivelmente outras, como veremos no tópico seguinte.

No amplo sentido, pode-se assinalar que, do ponto de vista do fundamento para a construção das utopias na educação, há pelo menos três motivações que no curso da história seguem construindo a "essência" para o processo educativo. Uma delas, talvez a mais clássica no âmbito da escola ocidental, tem seu eixo na ideia de Deus como perspectiva. Sob esse fundamento constituíram-se as pedagogias e os currículos da escola humanista moderna, destacadamente a pedagogia jesuítica com seu currículo baseado na Ratio Studiorum e as pedagogias luteranas com seus currículos focados na instrução moral e religiosa.

A outra tem sua perspectiva utópica na formação do "homem livre e esclarecido" e na ciência seu núcleo estruturante. Para Cambi (1999, p. 326), a educação [nesse contexto] emancipa-se dos modelos religioso-autoritários do passado e reivindica para o homem a formação de si próprio em seu processo de autonomia e de liberdade. Nesse âmbito formulam-se e desenvolvem-se um amplo conjunto de pedagogias genericamente denominadas de "renovadas" (LIBÂNEO, 2005; SAVIANI, 2005). Nelas, o currículo assume a perspectiva científica remodelando significativamente a matriz formativa. O que conta é o conhecimento socialmente relevante e a relação de utilidade do conhecimento para a vida dos sujeitos.

A terceira motivação de fundamento utópico tem na concepção materialista da história o pressuposto para o alcance da "emancipação humana”. Na perspectiva do materialismo histórico e dialético, o currículo 
é um artefato histórico-político que tem por finalidade oportunizar aos indivíduos a apropriação do saber elaborado (ciência) de modo que as gerações possam acessar o conhecimento historicamente produzido pela humanidade com vistas a transformação social.

No sentido do que vimos apontando para demonstrar a hegemonia do pensamento fundacional na constituição das pedagogias e do currículo, consideramos possível afirmar, acompanhando Karl Mannheim (1982), que a utopia é uma dimensão essencial da consciência histórica da modernidade e que o currículo se apresenta como um dos principais instrumentos institucionais ou a condição objetiva para conduzir a educação escolar na direção dos "sonhos" nutridos pelas pedagogias humanistas e pelos racionalismos que tão bem marcam esse período.

\section{Currículos que rejeitam perspectivas utópicas: elementos da dimensão pós-fundacional na educação escolar}

...la teoría social postmoderna ha excluido de sus prácticas la habilidad de pensar en términos de utopía (McLAREN, 2001a).

Consideramos possível afirmar logo de início que, no âmbito da educação, todas as correntes e tendências do pensamento pós-fundacional e/ou pós-moderno se desenvolvem ancoradas, de alguma forma, nos princípios da filosofia da existência. Essa matriz, de Friedrich Nietzsche (1844-1900) e Jean Paul Sartre (1905-1980), até Michel Foucault (19261984), Jacques Derrida (1930-2004) e Gilles Deleuze ${ }^{1}$ (1925-1995), com seus desdobramentos epistemológicos, vem reposicionando as ideias de formação humana e manifestando explícita desconfiança sobre a existência de qualquer forma de essência, de universalidade ou de verdade absoluta e, nesse sentido, vem questionando todas as abordagens que afirmam

1 Além dos filósofos citados, podemos acrescentar: Jean François Lyotard (1924-1998), Gianni Vattimo (1936) e Jürgen Habermas (1929), além de outros. 
haver ideais ou fins últimos para a educação. Nesse amplo e complexo campo teórico, as pedagogias se revelam diluídas em "relativismos" uma vez que, assumindo-se fragmentárias, descentradas, multirreferenciadas, ecléticas e, portanto, hibridas, colocam em "suspenso" todas as certezas teleológicas da formação humana e, por conseguinte, a tradição curricular construída no marco da "grande pedagogia moderna" (SILVA, 1996).

Para Sanches (2006), se as metanarrativas que corporizavam o pensamento da modernidade perderam hoje o caráter fundacional, é facilmente admissível que o próprio discurso pedagógico reflita o ímpeto da fratura epistemológico-axiológica que fez abalar o paradigma racionalista que o configurava. Notadamente é no espaço curricular onde a implicação dessa fratura mais se manifesta, até porque é nele, onde se operam os movimentos formativos, que se expressam as concepções de mundo de sociedade e de sujeito, estejam estas concepções em perspectivas filosófica, política, econômica ou cultural.

Cantista (1989, p. 343) recorre à Merleau-Ponty para referir-se ao pós-modernismo, destacando que nesse cenário "o pensamento eidetizado existencializa-se, pugna pela busca de suas raízes atuais, terrenas, tópicas, corpóreas. O pensamento é real, se se destutela de todo o apriorismo idealizante, de toda a pretensão absolutizadora, utópica, de sobrevoo".

Com certa facilidade, encontramos textos e obras do campo da filosofia, da filosofia da educação, da sociologia da educação e do próprio currículo, apontando as "desconstruções" continuamente feitas pelo pensamento pós-moderno, pós-estruturalista, pós-fundacional e pós-metafísico $^{2}$ nas "consolidadas racionalidades" que edificaram o humanismo idealista e pragmático da modernidade. Obviamente que os impactos dessa "desarrumação" (CHARLOT, 2006) nas formas de compreensão de mundo e de sociedade tornam-se claramente visíveis no campo da

2 Em face do objeto de análise e das limitações do presente texto não se explicitam aspectos conceituais sobre cada uma das abordagens mencionadas. 
educação. Para Hermann (1998) o debate educacional encontra-se atingido pelo naufrágio e pelas perdas do iluminismo.

Dentre os "mil pedaços" resultantes do estilhaçamento do pensamento moderno fundacional e utópico, os autores formuladores de uma consciência pós-moderna e/ou pós-fundacional reservam atenção especial a discussão sobre alguns aspectos educacionais os quais consideramos que estejam diretamente implicados no âmbito do currículo, dentre estes a compreensão sobre o que seja conhecimento, verdade, sujeito e formação e sobre qual o significado real de uma realidade. É, pois, na explicitação desses conceitos pela ótica pós-fundacional que buscamos argumentar sobre as razões do possível esfacelamento das utopias no âmbito das formulações teóricas do campo curricular.

Teóricos do campo do currículo têm se debatido em torno destas e de outras questões que, notadamente, atacam a tradição das grandes pedagogias. A desarrumação tem sido geral na medida em que toma muitos dos elementos da chamada "essencialidade" do currículo e os desconstrói sem nada sugerir. Giroux (1996) e McLaren (2001) são exemplos de curriculistas que demonstram preocupação com esse descompromisso da pedagogia pós-moderna. Se em 1978 o currículo foi considerado por J. Schwab como moribundo por lhe faltar princípios, teoria e métodos fortes, hoje ele parece esquizofrênico pela falta de qualquer referência.

Notadamente as abordagens pós-fundacionais que discutem o campo têm afirmado que a morte da tradição está decretada pelo fim de todas as certezas de verdade, dos axiomas científicos, das racionalidades, do conhecimento relevante e disciplinar. Desse modo, não há mais razão para prescrições curriculares, para o normativo dos planejamentos e das matrizes, para a seleção e hierarquização de saberes escolares dado que o percurso formativo é constituído por acontecimentos, contingências e narratividades de sujeitos descentrados e pela permanente construção e desconstrução de significantes. O que se pode afirmar nesse cenário é que existem práticas discursivas constituidoras de realidade fragmentárias e provisórias, que currículo é discursividade, é texto, é invenção, é ato e 
cotidiano, é singularidade e diferença, é mestiçagem e hibridismo, é emaranhado rizomático, é caos e errância infinita, são agenciamentos.

Neste âmbito, o conhecimento é substituído por prática discursiva por entender-se que o discurso é produtor de realidade e gerador de poder. Conhecimentos são sistemas simbólicos e linguísticos contingentes, são repertórios de sentidos dos quais alguns são selecionados para compor o currículo. Assim, os discursos pedagógicos e curriculares são atos de poder, o poder de significar, de criar sentidos e homogeneizá-los (LOPES, 2011). Como a própria autora afirma, na perspectiva antirrealista (portanto pós-fundacional), o currículo não é coisa alguma, cada uma das tradições curriculares é um discurso que se hegemonizou e que, nesse sentido, constituiu o objeto currículo, emprestando-lhe um sentido próprio (p. 40).

Nessa linha de entendimento, a verdade é sempre relativa, dado que é sempre justificação, argumento, crença, representação ${ }^{3}$. A verdade, como apontou Lyotard (2004) em A condição pós-moderna, é convenção social dependente de um único critério, o da performatividade. A ciência e o conhecimento não se encontram tão preocupados com a verdade, mas com a possibilidade de um uso prático e eficiente. A ciência não é mais que um tipo de discurso fundamentado na argumentação e feita de linguagem. Nessa perspectiva, a ideia de sentido universal do conhecimento ou a própria autoridade do conhecimento fica esvaziada, cedendo lugar a um "cosmos de micronarrativas" (COSTA, 2008).

No âmbito do currículo fragiliza-se, portanto, o que há de mais central - o conhecimento escolar. Se assumida essa perspectiva na/pela escola, praticar-se-á qual currículo, privilegiando-se quais saberes? Ou, como pergunta Lima (2009), será mesmo necessário prescrever fins para a vida individual ou coletiva, para bem educar ou para organizar socialmente uma comunidade de humanos? O fim da prescrição e da autoridade do conhecimento seria o fim da utopia curricular que projeta a formação dos sujeitos individuais e coletivos? De fato, sob essa perspectiva

3 Para maior entendimento sobre a discussão sobre relavitismo e verdade, sugere-se: Habermas (2004) e Rorty (1997). 
está decretado o fim da utopia na formação humana, dado que a transcendência é substituída pela imanência (VATTIMO, 1987). É um mundo sem projetos, sem futuro, sem finalidades.

\section{Fim das utopias ou reposicionamento de apostas?}

A emergência de perspectivas pós-fundacionais no campo do currículo escolar pode ser entendida mesmo como a primeira experiência histórica de uma distopia no campo da educação escolar? Esta é a pergunta que nos colocamos no início desse texto. Entendemos que a resposta a esta questão exige que consideremos o que ocorre no âmbito macrosocial em termos de tendências e perspectivas, sobretudo as de natureza econômica, política, cultural e educacional e a expressão desses movimentos na organização escolar atual. Exige que compreendamos o quadro da produção teórica do campo do currículo e as implicações dessa literatura tanto na formação dos educadores quanto na constituição das políticas curriculares e, finalmente, que compreendamos a própria organização escolar, particularmente os movimentos de reconfiguração curricular atualmente em pauta.

Em síntese, faz-se necessário que avaliemos até que ponto as abordagens pós-fundacionais, da educação, têm implicado na tessitura curricular das escolas - se esse movimento, de amplo espectro, está passando ao largo da experiência escolar ou se, por via da academia e das políticas curriculares, operam-se mudanças no interior da escola. Em outras palavras, se os ventos que anunciam o fim das utopias pedagógicas estremecem o edifício histórico das certezas apenas no plano das narrativas ou se efetivamente alteram práticas curriculares historicamente legitimadas pela educação escolar?

Nossa hipótese, como resposta provisória à questão, é que estamos atravessando o tempo dos reposicionamentos das apostas, e os sonhos da mudança são agora bem mais "diurnos", como indica Ernst Block (2005). O ideário utópico que tão bem marcou os movimentos sociais e 
políticos dos séculos XVIII e XIX e que estimulou as racionalidades fundacionais em termos de produção filosófica, científica e educacional é, aos poucos, substituído por formas prospectivas de antecipação de futuro ${ }^{4}$, igualmente fundacionais, mas estrategicamente engendradas com vistas a manutenção do modelo capitalista vigente. Esse fenômeno é perceptível também na educação que, do ponto de vista político, cada vez mais atende às expectativas desse projeto socioeconômico.

A nosso ver, o que está em jogo não é o pensamento fundacional ou a força da prescrição curricular. O que está esvaziado é o lugar da utopia nos termos de sua constituição histórica como sonho de "outro mundo" ou de um "mundo melhor". A descrença na possibilidade da mudança social não traduz a perda do sentido teleológico da educação burguesa neste início de século. Pelo contrário, há um grande projeto em marcha que coloca a educação e o currículo nos trilhos de uma só expectativa de futuro - a do homem produtivo para uma sociedade de mercado.

Sem exigir o mesmo conceito das utopias clássicas, podemos afirmar que as utopias pedagógicas permanecem regendo o movimento educacional atual. Basta ver que todos os projetos educacionais e os currículos que lhes dão sustentação material, são pensados com vistas a "modelos sociais ideais". Assim, há projeto educacional para uma sociedade ecologicamente sustentável, para uma sociedade planetária, para uma sociedade globalizada, para uma sociedade da diferença cultural, permanece um projeto para uma sociedade sem classes, enfim, há várias utopias em cena com currículos desenhados para cada uma delas.

Sanches (2006), ao discutir uma teoria da educação no cenário da pós-modernidade, avalia que neste cenário, onde atuam com força os projetos de planetarização tecnológica, de globalização econômica e de multiculturalidade social, a educação tende a alinhar-se adensando ainda mais sua configuração normativa em relação aos objetivos e conteúdos curriculares. O que aponta a pesquisadora portuguesa pode ser

4 Sobre formas prospectivas de antecipação de futuro ver THIESEN (2011). 
verificado no Brasil quando se analisa o que vem ocorrendo no âmbito das políticas curriculares.

De fato, encontram-se em marcha no Brasil vários projetos curriculares, os quais nada tem a ver com as abordagens pós-fundacionais fortemente presentes nos espaços da produção teórica do campo. Se por um lado a produção teórica sobre currículo, constituída em referências pós-estruturalistas, se avoluma por outro, ampliam-se as políticas curriculares sustentadas por abordagens fundacionais de perspectiva neoliberal, sobretudo propostas que sugerem a volta de um "currículo nacional" e propostas que objetivam a formação de competências e habilidades. Vale lembrar ainda que vários estados brasileiros mantêm suas políticas curriculares ancoradas em abordagens de filiação marxista, mantendo a busca de seus ideais mais universais.

O conceito de performatividade/prescrição nas políticas curriculares parece conviver, sem conversar, com o conceito de currículo discurso/texto presente nas abordagens pós- fundacionais, que tomam parte significativa da discussão teórica do campo no Brasil atualmente. Enquanto os últimos esforçam-se em demonstrar a inconsistência dos essencialismos, dos universalismos, das grandes narrativas epistemológicas e das utopias pedagógicas, os primeiros imprimem sua força política oferecendo alternativas e soluções curriculares para estados e municípios brasileiros.

Matéria publicada em jornal de circulação nacional que traz como manchete: "MEC vai propor currículo nacional para a educação básica" constitui um bom exemplo desse movimento. "Não vamos colocar o currículo numa forma, vamos discutir as bases. Não é uma listagem de conteúdos,é um instrumento de organização da vida do professor e do aluno", explica a então secretária de Educação Básica do MEC, Maria do Pilar Lacerda. Por sua vez, o ministro da Educação afirma que a ideia não é formatar um currículo único. "O Brasil praticamente aboliu o currículo nos anos 1990 e a Prova Brasil recuperou um pouco, pela via da avaliação,

5 Disponível em: <www.estadao.com.br/Educação>. Matéria publicada em 04 dez. 2011. 
a ideia de organização curricular, que estava fragmentada com os parâmetros curriculares" (ESTADÃO, 04 dez. 2011). Depreende-se que, pela expectativa oficial, sobretudo se considerada a política de avaliação que o país vem implantando em todos os níveis da educação, que a concepção é notadamente performativa ${ }^{6}$, isto é, focada em resultados.

Sem dúvidas, o que está colocada é a explicitação de um grande projeto econômico e político no qual a educação e o currículo estão subordinados. Com bem aponta Lopes (2008, p.21) "parte-se do reconhecimento de que, com o advento das políticas econômicas genericamente denominadas neoliberais, há acentuada submissão das políticas educacionais aos mecanismos de definição e de avaliação dos conteúdos curriculares pelo Estado, bem como aos mecanismos de regulação do mercado". Portanto, na concepção desse projeto, que articula presente e futuro, não há lugar para relativismos ou perda das prescrições curriculares. O que se apresenta como necessário é o ajustamento das estratégias nas diferentes atividades sociais, especialmente na educação, vista como imperativo do desenvolvimento capitalista.

Assim, entendemos que há um reposicionamento de apostas no campo da educação e que esse reposicionamento exige um conjunto de ajustes curriculares, muitos dos quais já estão sendo operados, seja pelo estado capitalista, por organismos multilaterais ${ }^{7}$ ou mesmo por organizações privadas. Não se trata, a nosso ver, de uma reforma curricular, entendida esta como alternativa educacional para uma mudança social. Trata-se de ajustes instrumentais e normativos, já que os princípios fundamentais que orientam a educação burguesa seguem sendo os mesmos que sustentaram o liberalismo clássico, o pragmatismo anglo-saxão e agora

6 Sobre o conceito de performatividade em currículo sugere-se a leitura do texto: A performatividade nas políticas de currículo: o caso do ENEM. (LOPES e LÓPEZ, 2008)

7 No documento de apresentação do PISA 2010 se pode ler: "A educação é o investimento mais crítico para aumentar o potencial de crescimento a longo prazo dos países. Na economia global, o desempenho dos sistemas de educação é a chave para o sucesso, especialmente à luz dos desafios fundamentais tecnológicos e demográficos que estão remodelando nossa economia" (OCDE, 2010). 
o neoliberalismo da sociedade de mercado. Como avaliou Apple (1985, 2002), nas reformas curriculares da direita neoconservadora há pouca atenção à problemática das desigualdades sociais, dado que sua meta é ampliar as formas de regulação social por mensuração de resultados. Parece-nos que a mudança de estratégia é a estratégia para a permanência.

De modo geral, se pode afirmar que o reposicionamento das estratégias ocorre pelo adensamento de algumas políticas e pelo arrefecimento de outras. Em nível global é possível observar, por exemplo, maior participação dos organismos internacionais nas questões educacionais e curriculares; há uma evidente abertura para a participação das organizações do setor privado na oferta de alternativas curriculares inclusive para escolas públicas; há maior presença de mecanismos de avaliação externa sobre os resultados curriculares de aprendizagem das escolas; há uma gradativa fragilização das políticas de descentralização curricular, sobretudo pelo ranqueamento das instituições por provas e testes.

Assim, observa-se que tanto no atual cenário da educação mundial, quanto da política curricular dela decorrente, não há evidências de fragilização do pensamento fundacional ou de esgotamento das utopias pedagógicas. O que se observa é o deslocamento das estratégias sem, obviamente, alteração das finalidades. A grande pedagogia continua sendo a burguesa, a grande finalidade continua sendo a formação de sujeitos produtivos e a grande utopia segue sendo alcançar uma sociedade democrática de fundamento liberal.

\section{Referências}

APPLE, M. Ideologia e Currículo. São Paulo: Brasiliense, 1982.

APPLE, M. Podem as pedagogias críticas sustar as políticas de direita? Cadernos de Pesquisa, n. 116, p. 107-142, jul. 2002.

ARAÚJO, J. M. de; ARAÚJO, A. F. Utopia e educação. Revista Portuguesa de Pedagogia, Universidade de Coimbra, v. 40, n. 1, 2006. 
ARROYO, M. G. Currículo, território em disputa. Petrópolis: Vozes, 2011.

BLOCH, E. O Princípio Esperança. v. 1. Trad. Nélio Schneider. Rio de Janeiro: EDUERJ, Contraponto, 2005.

CAMBI, F. História da Pedagogia. São Paulo: Fundação editora da UNESP, 1999.

CANTISTA, M. J. P. A noção de profundidade no pensamento postmoderno: supostos e repercussões. Revista da Faculdade de Letras, Universidade do Porto, $n$. 06, 1989. (Série filosofia.

CHARLOT, B. A pesquisa educacional entre conhecimentos, políticas e práticas: especificidades e desafios de uma área de saber. Revista Brasileira de Educação, v. 11, n. 31, p. 7-18, 2006.

COMENIUS, J. A. Didática magna. São Paulo: Martins Fontes, 1997.

COSTA, J. As voltas do Pós-modernismo. Revista Lucense de Linguística \& Literatura, Santiago de Compostela, v. 14, 2008.

COX, C. El curriculum escolar del futuro. Revista Perspectivas, Universidad de Chile, v. 4, n. 2, p. 213-232, 2001.

FULLAT, O. Filosofias da educação. Petrópolis: Vozes, 1995.

GIROUX, H. Educación posmoderna y generación juvenil. Nueva Sociedad, n. 146, nov./dici., 1996.

GUIDINI, F.; MARTINS, P. L. O. Pedagogia da essência: contexto, princípios, relações. In: IX Congresso Nacional de Educação - EDUCARE. Disponível em: <http:// www.pucpr.br/eventos/educere/educere2009/anais/pdf/2556_1289.pdf〉. Acesso em: 03 de jan. 2013.

HABERMAS, J. Verdade e Justificação: ensaios filosóficos. Trad. Milton Mota. Edições Loyola, 2004.

HERMANN, N. O polêmico debate da educação na contemporaneidade: a contribuição habermasiana. In: ZUIN, A. et al. A educação danificada: contribuições à teoria crítica da educação. Rio de Janeiro: Vozes, 1998. 
LIBÂNEO, J. C. Didática. São Paulo: Cortez Editora (23ª. Edição), 2005.

LIMA, João Francisco Lopes de. A educação, a pós-modernidade e a crise de fundamentação do discurso pedagógico. Cadernos de Pesquisa: pensamento educacional, v. 4, n. 7, 2009. Disponível em: <http://www.utp.br/Cadernos_de_Pesquisa/ pdfs/cad_pesq7/17_a_educacao_a_pos_cp7.pdf >. Acesso em: 17 jan. de 2013.

LOPES, A.; MACEDO, E. Teorias de currículo. São Paulo: Cortez, 2011.

LOPES, A. Políticas de integração curricular. Rio de Janeiro: Eduerj, Faperj, 2008.

LOPES, A.; LÓPEZ, S. B. A performatividade nas políticas de currículo: o caso do ENEM. Educação em Revista, Belo Horizonte, v. 26, n. 1, p. 89-110, abr. 2010.

LYOTARD, J.-F. A condição pós-moderna. $8^{\mathrm{a}}$ ed. Jose Olympio: Rio de Janeiro, 2004.

MANNHEIM, K. Ideologia e utopia. Rio de Janeiro: Editora Zahar, 1982.

MARCHART, O. El pensamiento político posfundacional: La diferencia política en Nancy, Lefort, Badiou y Laclau. Buenos Aires: F. C. Económica, 2009.

MCLAREN, P. La posmodernidad y la muerte de la política: el indulto brasileño. In: ALBA, A. (ed.). Postmodernidad y educación. México: Porrúa, 1995.

McLAREN, P. A pedagogia da utopia. Santa Cruz do Sul: EDUNISC, 2001.

MCLAREN, P. Fúria e Esperança: A pedagogia revolucionária de Peter McLaren. Currículo sem Fronteiras, v. 1, n. 2, p. 171-188, jul./dez. 2001.

MOREIRA, A. F. B. Currículo, utopia e pós-modernidade. Currículo questões atuais, São Paulo: Papirus, 1997.

NARODOWSKI, M. El final de las utopías educativas. Un adiós sin penas ni olvidos. Revista Contextos de Educación, Universidad Nacional de Quilmes, 2009. Disponível em: <http://www.unrc.edu.ar/publicar/cde/ 2h1.html>.

OCDE.PresentationofthePISA2010Results.2010.Disponívelem:http://www.oecd. org/document/7/0,3746,en_21571361_44315115_46635719_1_1_1_1,00. htm>. Acesso em: 10 de jan. de 2012 
PIOZZI, P. Utopias revolucionárias e educação pública: Rumos para uma nova cidade ética. Revista Educação e Sociedade, Campinas, v. 28, n. 100 (especial), p. 715-735, out. 2007.

RORTY, R. Objetivismo, relativismo e verdade. Trad. Marco Antônio Casanova. Rio de Janeiro: Relume-Dumará, 1997.

SANCHES, M. F. Desafios a uma teoria da educação na pós-modernidade. Revista Portuguesa de Pedagogia, Ano 40-2, 225-236, 2006.

SAVIANI, D. Pedagogia Histórico-Crítica: primeiras aproximações. 9. ed. Campinas: Autores Associados, 2005.

SCHWAB, J.L. Science, curriculum and liberal education. In: WESTBURY, I; WILKOF, N. Chicago: The University of Chicago Press, 1978.

SILVA, T. O adeus às metanarrativas educacionais. In: SILVA, T. Identidades Terminais. Petrópolis: Vozes, 1996.

SUCHODOLSKI, B. A pedagogia e as grandes correntes filosóficas. Lisboa: Livros Horizonte, 1978.

THIESEN, J. S. A educação do futuro: contribuições da gestão do conhecimento. São Paulo: Papirus, 2011.

VATTIMO, G. O fim da modernidade - niilismo e hermenêutica na cultura pós-moderna. Lisboa: Editorial Presença, 1987.

YOUNG, M. F. D. O currículo do futuro, da nova sociologia da educação a uma teoria crítica do aprendizado. São Paulo: Papirus, 2002.

Recebido: 11/06/2016

Received: 06/11/2016

Aprovado: 20/10/2016

Appoved: 10/20/2016 
